\title{
Ideas previas y detección del error en la deconstrucción y reconstrucción de saberes
}

\author{
Macedo, M. Florencia*; Illesca, Paola*; Fuentes, Marta B.*; \\ Costamagna, Alicia M.T.*
}

\section{Resumen}

Una concepción constructivista del aprendizaje señala tres elementos que determinan el estado de los alumnos al iniciar el proceso del saber: disposición, capacidad y conocimientos previos.

Las ideas previas sobre los conceptos científicos que tienen los alumnos son algunas veces erróneas y deben tenerse en cuenta como condición necesaria para un aprendizaje significativo.

Por otra parte, el docente suele desvalorizar o castigar el error, cuando debería proponerlo como paso previo a la construcción del conocimiento, para favorecer la búsqueda de procesos de deconstrucción y reconstrucción.

Con el objeto de detectar modificaciones de las ideas previas mediante la identificación y superación del error, alumnos de la cátedra de Morfología Normal respondieron una evaluación diagnóstica anónima.

Al finalizar el cursado, dicho pre-test fue sometido a una co-evaluación con señalamiento de los errores, a fin de dar cuenta de la reconstrucción de los saberes, lograda durante el proceso de enseñanza-aprendizaje.

La evolución positiva de las respuestas, entre el pretest y el postest, expresa un cambio conceptual significativo y reafirma la importancia de la consideración de las ideas previas.

* Cátedra Morfología Normal

Facultad de Bioquímica y Ciencias Biológicas. 